\title{
N-Alkylation of 2-methoxy-10H-phenothiazine revisited. A facile entry to diversely N- substituted phenothiazine-coumarin hybrid dyes
}

\author{
Valentin Quesneau ${ }^{\mathrm{a}, *, *}$, Kévin Renault $^{\mathrm{a}}$, , Myriam Laly ${ }^{\mathrm{a}}$, Sébastien Jenni ${ }^{\mathrm{a}}$, Flavien Ponsot ${ }^{\mathrm{a}}$, Anthony \\ Romieu $^{\mathrm{a} \text {,* }}$
}

${ }^{a} I C M U B$, UMR 6302, CNRS, Univ. Bourgogne Franche-Comté, 9, Avenue Alain Savary, 21078 Dijon cedex, France

$\mathrm{N}$-Alkylation of 2-methoxy-10H-phenothiazine, a valuable building block for the synthesis of bioactive compounds and reaction-based fluorescent probes, has been revisited aimed at introducing a substituent easily convertible into cationic or zwitterionic side chains. We focused our attention on the 3-dimethylaminopropyl group since its derivatization through reactions with various alkyl halides or sultones is a well-established and effective way to enhance polarity of diverse hydrophobic molecular scaffolds. This two-step functionalization approach was applied to the synthesis of novel phenothiazine-coumarin hybrid dyes whose spectral features, especially their NIR-I emission, have been determined in aqueous media with the ultimate goal of identifying novel fluorescent markers for bioanalytical applications, including fluorogenic detection of reactive oxygen species (ROS) through selective S-oxidation reaction of phenothiazine scaffold.

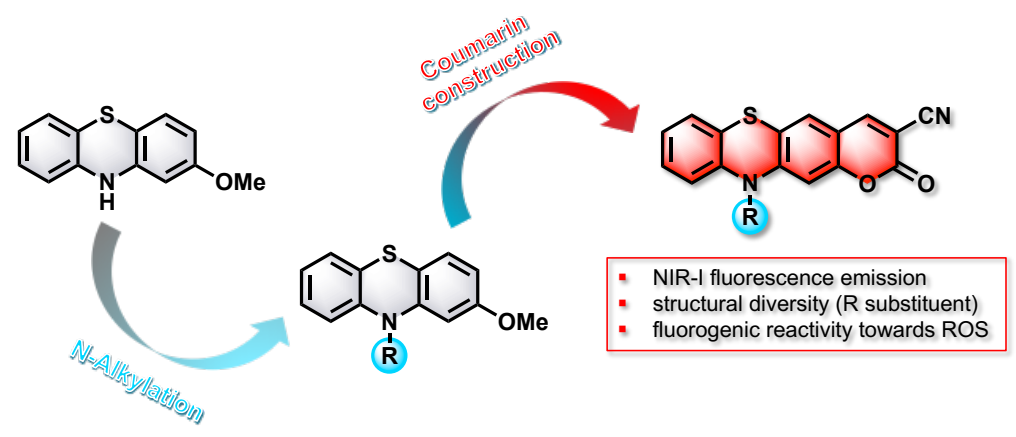

\section{Introduction}

Since the discovery and first syntheses of methylene blue (MB) [1] and 10H-dibenzo-1,4-thiazine (PTZ) [2] in the late $19^{\text {th }}$ century (Fig. 1), the interest shown by the scientific community (especially chemists and biologists) for phenothiazine derivatives has exploded [3]. This is notably reflected in the fact that there are many thousands of different molecules belonging to this class of $\mathrm{N}, \mathrm{S}-$ heterocycles, and finding diverse applications in industry (e.g., as dyestuffs, antioxidants in lubricants and fuels, polymerization inhibitors, ...) and medicine (e.g., as antipsychotic medications, (photo)therapeutic agents, biological staining/labeling agents, ...) [4]. Aside from these traditional usages, PTZ-based molecular systems endowed with remarkable electronic properties, have recently found further applications in optoelectronics (e.g., bulk hetero-junction solar cells, dye sensitized solar cells, organic light emitting diodes, ...) [5] and fluorescent sensing and bioimaging [6]. Among the myriad PTZ derivatives with different substitution patterns, some of them are constructed from the structurally simple building block 2methoxy-10H-phenothiazine 1 (Fig. 1). They have been recently popularized either as long-wavelength fluorescent dyes [7] or as fluorogenic probes in the field of activity-based sensing. In this latter context, they are effective tools for detecting reactive analytes (e.g., phosgene, $\mathrm{SO}_{2}$, thiophenol) in different matrices or tracking relevant species in biological systems (e.g., ROS/RNS, $\mathrm{H}_{2} \mathrm{~S}_{\mathrm{n}}$ ), for analytical and diagnostics purposes respectively (see Fig. 1 for selected examples) [8]. Curiously, the vast majority of these reaction-based fluorescent probes and related fluorophores display minor structural changes in their PTZ ring, which severely limits opportunities for fine-tuning their spectral and physicochemical properties (e.g., solubility in water) and/or installation of a suitable handle for bioconjugation to perform fluorescent biolabeling or to dramatically enhance their performances as imaging agents (e.g., targeting properties). A good illustration of this fact is $N$-substituent (i.e., the 10-position of PTZ) found in the core structure of its photoactive PTZ-based compounds. This is always a simple alkyl chain (i.e., ethyl or butyl substituent) whereas this position may be better exploited to introduce a post-synthetically derivatizable reactive group such as amino, carboxylic acid, or hydroxyl. To the best of our knowledge, few examples of such $\mathrm{N}$-substituted derivatives of 2-methoxy$10 H$-phenothiazine have been described in the literature even if several modulations of its $\mathrm{N}-10$ substituent were regarded in effort to identify new drugs [9].

In order both to fill this gap and to devise a novel approach towards PTZ molecular diversity, we thought it would be interesting to revisit $\mathrm{N}$-alkylation of 2-methoxy- $10 \mathrm{H}$-phenothiazine to introduce a substituent easily convertible into another group. Inspired by the structure of levomepromazine (maleate salt, Fig. 1), a neuroleptic drug used in palliative care and developed in the 1960s by a Japanese company namely Yoshitomi Pharmaceutical Industries [10], we have rapidly identified 3-dimethylaminopropyl moiety as the appropriate substituent to achieve this goal. It is worth mentioning that the use of this tertiary-amine-terminated alkyl chain or related analogs was popularized for the watersolubilization of various organic-based fluorophores, through their site-specific introduction and post-synthetic quaternarization with

\footnotetext{
${ }^{*}$ Corresponding authors. Tel.: +33-3-80-39-61-26 or +33-3-80-39-36-24; e-mail: valentin.quesneau@u-bourgogne.fr or anthony.romieu@ubourgogne.fr.
}

$\$$ These authors contributed equally to this work. 
alkyl halides or sultones, thereby yielding positively-charged or zwitterionic dyes [11],[12]. Similarly to PTZ uses, diketopyrrolopyrroles (DPPs), a class of industrial pigments known since the early 1970 s, were recently applied as promising fluorescent organic dyes owing to their valuable spectral properties [13] but curiously, this $\mathrm{N}$-functionalization strategy was never applied to these bis-lactam-based molecules. Indeed, Nalkylation of these cyclic amide moieties is often the preferred way to convert DPP pigments into soluble dyes, and the practical implementation of this reaction with versatile 3dimethylaminopropyl substituent, would deserve to be explored to meet demands in molecular diversity for such photoactive compounds. Indeed, the current available methods are based on formal exchange and/or post-functionalization of 3,6-(hetero)aryl substituents, and are sometimes tricky and/or require de novo synthesis [13c, 14].

In this Letter, we report our findings related to optimization of the $N$-alkylation of $\mathbf{1}$ with butyl bromide and 3dimethylaminopropyl chloride. A comparison with the reactivity of selected DPP pigments was also established. The availability of $\mathrm{N}$-substituted 2-methoxyphenothiazine derivative 3 led us to consider the synthesis and photophysical characterization of novel PTZ-coumarin hybrid dyes. Their ability to act as ratiometric fluorescent chemodosimeters for hypochlorous acid/hypochlorite $\left(\mathrm{HClO} / \mathrm{ClO}^{-}\right)$detection, through oxidation of their sulfur atom was finally assessed.

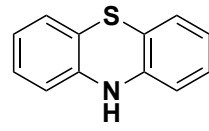

10H-Dibenzo-1,4-thiazine (PTZ)

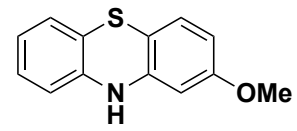

2-Methoxyphenothiazine 1<smiles>CN(C)c1ccc2nc3ccc(=[N+](C)C)cc-3sc2c1</smiles>

Methylene blue (MB)

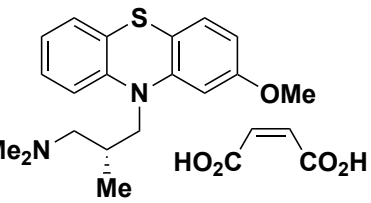

Levomepromazine (maleate salt)<smiles>CCN1c2ccccc2Sc2cc(-c3nc4c5ccccc5c5ccccc5c4[nH]3)c(O)cc21</smiles>

"OFF-ON" probe responsive to phosgene (dual N,O acylation reaction)<smiles>N#Cc1ccc(N=Cc2cc3c(cc2O)N(Cc2ccccc2)c2ccccc2S3)cc1</smiles>

$\mathrm{Bu}$

Ratiometric probe responsive to $\mathrm{SO}_{2}$ ( $\mathrm{Nu}$ addition of $\mathrm{HSO}_{3}^{-}$on $\mathrm{C}=\mathrm{N}$ )

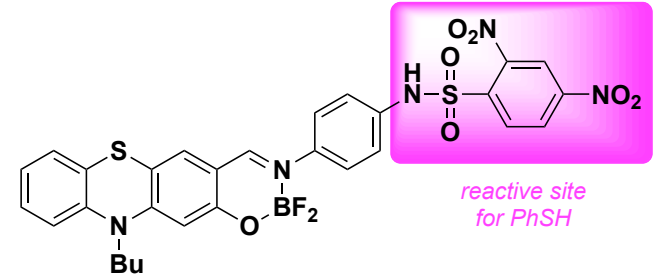

"OFF-ON" probe responsive to thiophenol (deprotection of $\mathrm{NH}_{2}$ group by thiolysis of sulfonamide)<smiles>O=[SH]c1cc(-c2nc3ccccc3s2)c(OCCN2CCOCC2)cc1N(Cc1ccccc1)c1ccccc1</smiles>

Ratiometric probe responsive to hypochlorus acid (sulfur atom oxidation mediated by $\mathrm{ClO}^{-}$)

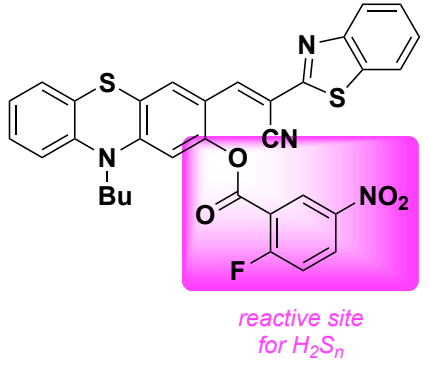

"Covalent-assembly" probe responsive to $\mathrm{H}_{2} \mathrm{~S}_{n}$ (phenol deprotection through a tandem $S_{N}$ Ar/cyclization reaction, followed by Pinner cylization)

Fig. 1. (Top) Structures of 10H-dibenzo-1,4-thiazine, 2-methoxy-10H-phenothiazine and methylene blue; (bottom) selected examples of reaction-based fluorescent probes (intensiometric "OFF-ON" or ratiometric response) bearing a PTZ photoactive scaffold $\left(\mathrm{Bu}=n\right.$-butyl, $\mathrm{COCl}_{2}=$ phosgene, Et $=$ ethyl, $\mathrm{H}_{2} \mathrm{~S}_{\mathrm{n}}=$ hydrogen polysulfides, $\mathrm{PhSH}=$ thiophenol and $\mathrm{SO}_{2}=$ sulfur dioxide) [8m],[8i],[8b],[8h],[8e].

\section{Results and discussion}

\section{Optimization of N-alkylation of 2-methoxyphenothiazine 1}

As illustrated by the examples displayed in Fig. 1, N-alkyl 2hydroxyphenothiazine moiety is the structural unit common to a wide range of analyte-responsive PTZ-based fluorescent probes. The first stages of their multi-step preparation are aimed to achieve the conversion of commercial 2-methoxyphenothiazine $\mathbf{1}$ into the corresponding $\mathrm{N}$-alkyl salicylaldehyde derivative (Scheme 1). Thus, N-substitution of PTZ scaffold with $n$-butyl bromide or ethyl iodide, was achieved by treatment of $\mathbf{1}$ with a large excess of this alkylating reagent (10 equiv.), in the presence of $\mathrm{NaOH}$ and cat. amount of KI in the case of 1-bromobutane, in dry DMSO heated above $100{ }^{\circ} \mathrm{C}$ [8a], but experimental details for such reactions are often omitted and only reference to former publications was given. In our hands, these conditions led to disappointing results and especially, the degradation of phenothiazine ring system was observed. A literature survey on the preparation of levomepromazine and related N-alkyl PTZ derivatives revealed the use of other strong bases such as $\mathrm{NaNH}_{2}$ or $\mathrm{NaH}$ to perform such $\mathrm{N}$-alkylation reaction, often conducted in an aromatic hydrocarbon solvent (toluene or xylene) possibly in mixture with DMSO or DMF $[6 i, 10,15]$. By drawing on these previous works, we have devised a new protocol based on the treatment of 1 with 2 equiv. of $n$-butyl bromide, in the presence of 2 equiv. of $\mathrm{NaH}$ in 
dry DMF at room temperature, that provided the desired N-butyl derivative 2 with a good isolated $85 \%$ yield within 90 min (and deployable to gram scale synthesis, Scheme 1). At this stage, it seemed relevant for us to expand the scope of this optimized protocol to more sophisticated alkyl pendant arms bearing a further reactive group for post-synthetic functionalization of PTZ heterocycle. Thus, N-alkylation of $\mathbf{1}$ with commercial 3dimethylaminopropyl chloride ( $\mathrm{HCl}$ salt) conducted under the same conditions, was next considered and the desired product 3 was obtained with a modest $23 \%$ yield. No substantial improvement was obtained with the mesylate derivative freshly prepared from 3-dimethylamino-1-propanol. These results are consistent with those previously obtained by us with unsymmetrical DPP pigments 4-6 (Scheme 1) for which the Nalkylation of lactam moieties is essential to impart to them both solubility and functionality. Indeed, reaction of 4 with 3dimethylaminopropyl chloride ( $\mathrm{HCl}$ salt, 10 equiv., previously neutralized with 10 equiv. of $\mathrm{NaH})$, in the presence of $\mathrm{NaH}(5.5$ equiv) and tetrabutylammonium iodide (TBAI, 0.05 equiv) in dry DMF at $80{ }^{\circ} \mathrm{C}$ provided bis-N,N'-substituted DPP dye 7 with an isolated $29 \%$ yield. Conversely, no trace of bis-N,N'-alkylated derivative was detected when unsymmetrical DPP pigments $\mathbf{5}$ and $\mathbf{6}$ were subjected to the same alkylation conditions. This perfectly illustrates how difficult it is to generalize this functionalization strategy that may sound simple on paper. Furthermore, it is important to specify that the major difficulty associated with this alkylation reaction is closely related to the high propensity of 3dimethylaminopropyl halide (or mesylate) to react with itself leading to its self-polymerization or premature quaternarization of dimethylamino group pre-introduced onto the fluorophore scaffold. Thus, the above-mentioned reaction has led to a mixture of 7 and $\mathbf{8}$ in the ratio 78:22 and our further attempts to minimize the quaternarized-related side-product formation failed.

Both optimized N-alkylation methods of 2methoxyphenothiazine heterocycle can readily provide hundreds of milligrams of $\mathbf{2}$ and $\mathbf{3}$. We wished to valorize these building blocks in the synthesis of phenothiazine-coumarin hybrid dyes [7], with the dual aim of accurately determining the spectral properties of these NIR-I emitters under simulated physiological conditions, and confirming the chemical inertness of $\mathrm{N}$-alkyl pendant arm during multi-step synthetic processes.
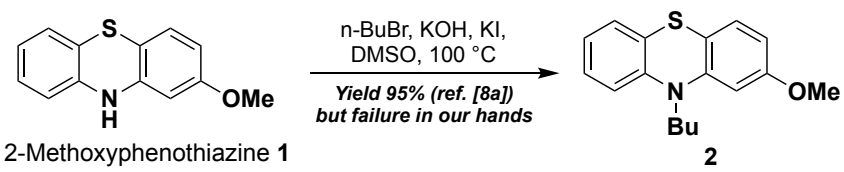

2-Methoxyphenothiazine 1
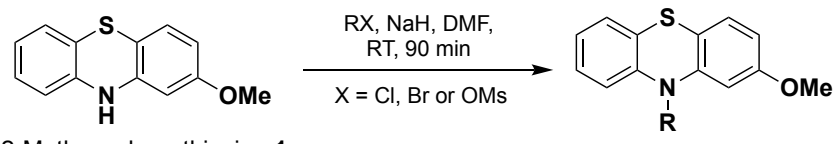

2, $\mathrm{R}=\mathrm{Bu}$, yield $85 \%$

$3, \mathrm{R}=\mathrm{NMe}_{2}$,

yield $23 \%$

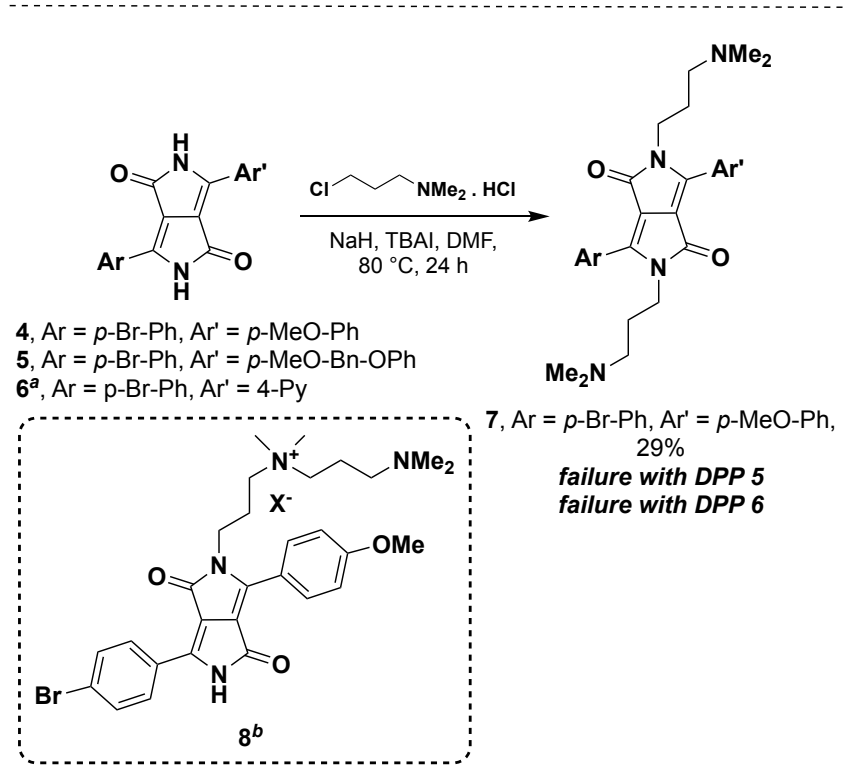

Scheme 1. (Top) Background information and revisited N-alkylation of 2methoxyphenothiazine with $n$-butyl bromide and 3-dimethylaminopropyl chloride (HCl salt); (bottom) N-Alkylation of DPP pigments with 3dimethylaminopropyl chloride $(\mathrm{HCl}$ salt $)(p-\mathrm{Br}-\mathrm{Ph}=$ para-bromophenyl, $\mathrm{p}$ $\mathrm{MeO}-\mathrm{Ph}=$ para-methoxyphenyl, $\mathrm{p}-\mathrm{MeO}-\mathrm{Bn}-\mathrm{OPh}=$ paramethoxybenzyloxyphenyl, 4 -Py $=4$-pyridyl, $\mathrm{RT}=$ room temperature, $\mathrm{TBAI}=$ tetrabutylammonium iodide, $\mathrm{X}^{-}=\mathrm{Cl}^{-}$or $\left.\mathrm{I}^{-}\right)$. ${ }^{a}$ Please note: for this DPP, only 3 equiv. of alkylating agent was used and a mixture of $N$-alkyl pyridinium and mono $N$-substituted lactam derivative was obtained. ${ }^{b}$ Please note: an alternative structure for this side-product may be the N,O-dialkyl DPP derivative.

\section{Synthesis of PTZ-coumarin hybrid dyes 10, 15 and 16}

Coumarins fused with other (hetero)aromatic units have been recently identified as attractive fluorescent markers for performing biosensing/bioimaging operations within the far-red or NIR-I spectral region [16]. Among the myriad of $\pi$-expanded coumarins currently available and already studied in this context, $4 \mathrm{H}$ benzo[1,4]thiazine-fused compounds (also known as phenothiazine coumarin hybrids) have been used to produce a fluorescence output upon the selective activation of "covalentassembly" type probes by targeted (bio)analytes (see Fig. 1 for example of $\mathrm{H}_{2} \mathrm{~S}_{\mathrm{n}}$-responsive probe) [8a, 8e, 8k, 81]. A multi-step synthesis based on the preparation of the key intermediate $\mathrm{N}$-alkyl 2-hydroxy-10H-phenothiazine-3-carboxaldehyde (through Vilsmeier-Haack formylation followed by deprotection of the methoxy group) and its subsequent Knoevenagel condensation with a latent $C$-nucleophile (e.g., malononitrile, heteroarylacetonitriles) complemented by an acid hydrolysis of iminolactone to lactone, was devised to access to a set of PTZ-coumarin hybrid dyes diversely substituted at the C-3 position. Both N-alkyl PTZ derivatives $\mathbf{2}$ and $\mathbf{3}$ have been subjected to this reaction sequence (Scheme 2). Formylation with $\mathrm{POCl}_{3} / \mathrm{DMF}$ yielded the 
corresponding PTZ-based ortho-anisaldehydes 9 and 11 both in good yields, which supports the fact that the presence of tertiary amino group on $\mathrm{N}$-alkyl pendant arm did not interfere with in situ generated chloroiminium ion. Deprotection of aryl methyl ether was achieved with $\mathrm{AlI}_{3}$, generated in situ from aluminum powder and iodine in dry $\mathrm{MeCN}$. From a practical point of view, we found that the use of a carousel-type parallel reaction station is particularly needed for effective gram scale synthesis of PTZbased salicylaldehyde 12 because of the low yield obtained when the reaction was performed at hundreds of $\mathrm{mg}$ scale, in a single batch. This method was found to prevent partly the undesired deactivation of $\mathrm{AlI}_{3}$ by the dimethylpropylamino group and through strong Lewis acid-base complexation, and a satisfying yield of $63 \%$ was obtained for 12 (to compare to $92 \%$ for N-butyl derivative 9). Next, chemoselective $N$-alkylation of $\mathbf{1 2}$ was performed either with methyl iodide to obtain cationic derivative 13 or 1,3-propanesultone to install a zwitterionic side-chain onto PTZ scaffold (compound 14). Both reactions were conducted without base to avoid undesired O-alkylation reaction (10-20 equiv. of alkylating reagent, in dry DCM at $40{ }^{\circ} \mathrm{C}$ for $17-24 \mathrm{~h}$ ). Finally, the three PTZ-coumarin hybrid dyes 10, 15 and 16 were synthesized through Knoevenagel condensation reaction with malononitrile under conventional conditions previously optimized by us. All purifications were achieved by semi-preparative RP-
HPLC under acidic conditions (i.e., linear gradient of $\mathrm{MeCN}$ in aq. TFA $0.1 \%, \mathrm{pH} 1.9)$ that enable both conversion of 2iminocoumarins into coumarins $\mathbf{1 0}, \mathbf{1 5}$ and $\mathbf{1 6}$, and their isolation in a pure form $(>95 \%)$ required for photophysical studies (vide infra). After recovery by freeze-drying, we noted that the solid form of zwitterionic PTZ-coumarin hybrid dye 16, is poorly soluble in water and polar organic solvent such as DMF, DMSO, $\mathrm{MeCN}$ and $\mathrm{MeOH}$. To overcome this solubility problem, a further counter-ion exchange operation was performed by semipreparative RP-HPLC using aq. triethylammonium bicarbonate buffer (TEAB, $50 \mathrm{mM}, \mathrm{pH}$ 7.5) and $\mathrm{MeCN}$ as eluents. Unfortunately, the benefit was found to be negligible. All spectroscopic data (see Supplementary data for the corresponding spectra, Figs. S8-S10, S13, S33-S36, S39, S43-S44 and S47), especially NMR and mass spectrometry, were in agreement with the structures assigned. The purity of each coumarin sample was confirmed by RP-HPLC analysis with UV-vis detection at different wavelengths, and mass percentage of TFA was determined by ionic chromatography (see Supplementary data, Figs. S11-S12, S37-S38 and S45-S46).

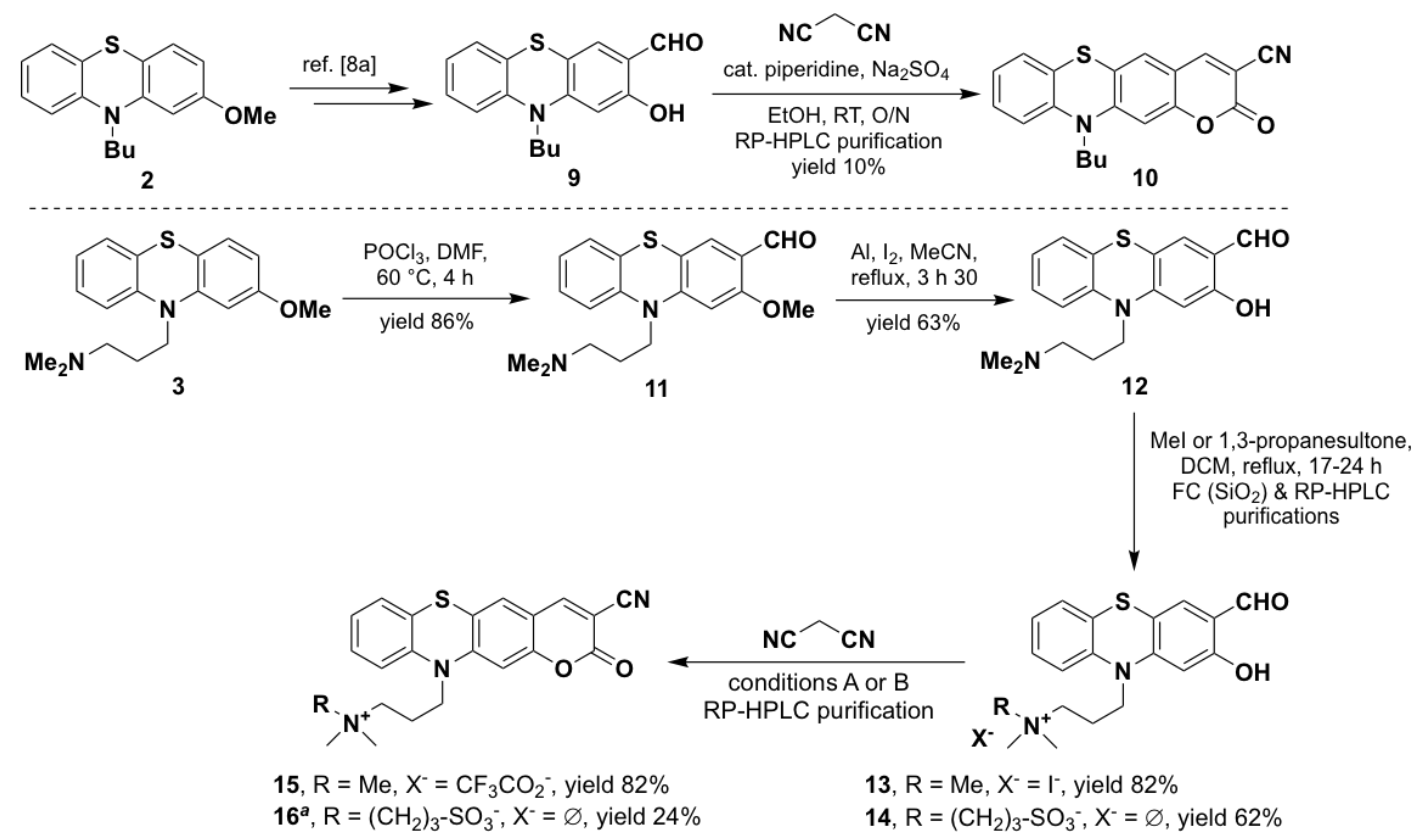

Scheme 2. (Top) Synthesis of PTZ-coumarin hybrid dye $\mathbf{1 0}$ from N-butyl 2-methoxyphenothiazine 1; (bottom) synthesis of cationic and zwitterionic PTZ-coumarin hybrid dyes 15 and 16 from N-(3-dimethylaminopropyl) 2-methoxyphenothiazine 3: conditions A for 15= piperidine, EtOH-MeCN (1:1, v/v), RT, 16 h; conditions $\mathrm{B}$ for $\mathbf{1 6}=$ piperidine, anhydrous $\mathrm{Na}_{2} \mathrm{SO}_{4}, \mathrm{EtOH}-\mathrm{DMF}(8: 1, \mathrm{v} / \mathrm{v}), \mathrm{RT}, 16 \mathrm{~h} .\left(\mathrm{O} / \mathrm{N}=\right.$ overnight, $\mathrm{FC}\left(\mathrm{SiO}_{2}\right)=$ flash-column chromatography over silica gel, $\mathrm{RT}=$ room temperature). ${ }^{a}$ Please note: compound 16 was isolated as triethylammonium salt. 


\section{Photophysical characterization of PTZ-coumarin hybrid dyes}

Although several PTZ-coumarin hybrid dyes, especially the derivative 17 bearing a 2-benzothiazolyl (BZT) moiety as C-3 substituent, have already been implemented in different biosensing operations $[8 \mathrm{a}, 8 \mathrm{e}]$, their spectral features have never been determined in pure aq. buffers that mimic physiological conditions. To fill this gap, we assessed the optical photophysical properties of 10, 15 and $\mathbf{1 6}$ in phosphate buffered saline (PBS, $\mathrm{pH}$ 7.3) alone but also in the presence of a non-ionic surfactant (Tween ${ }^{\circledR} 80$ ) to disrupt potential formation of aggregates. Further spectral measurements in $\mathrm{MeOH}$ were also achieved. All results are summarized in Table 1 (see Fig. 2 for the absorption/fluorescence spectra of $\mathbf{1 0}$ and Supplementary data for the absorption/fluorescence spectra of compounds $\mathbf{1 5}$ and 16, Figs. S40-S42 and S48-S50).
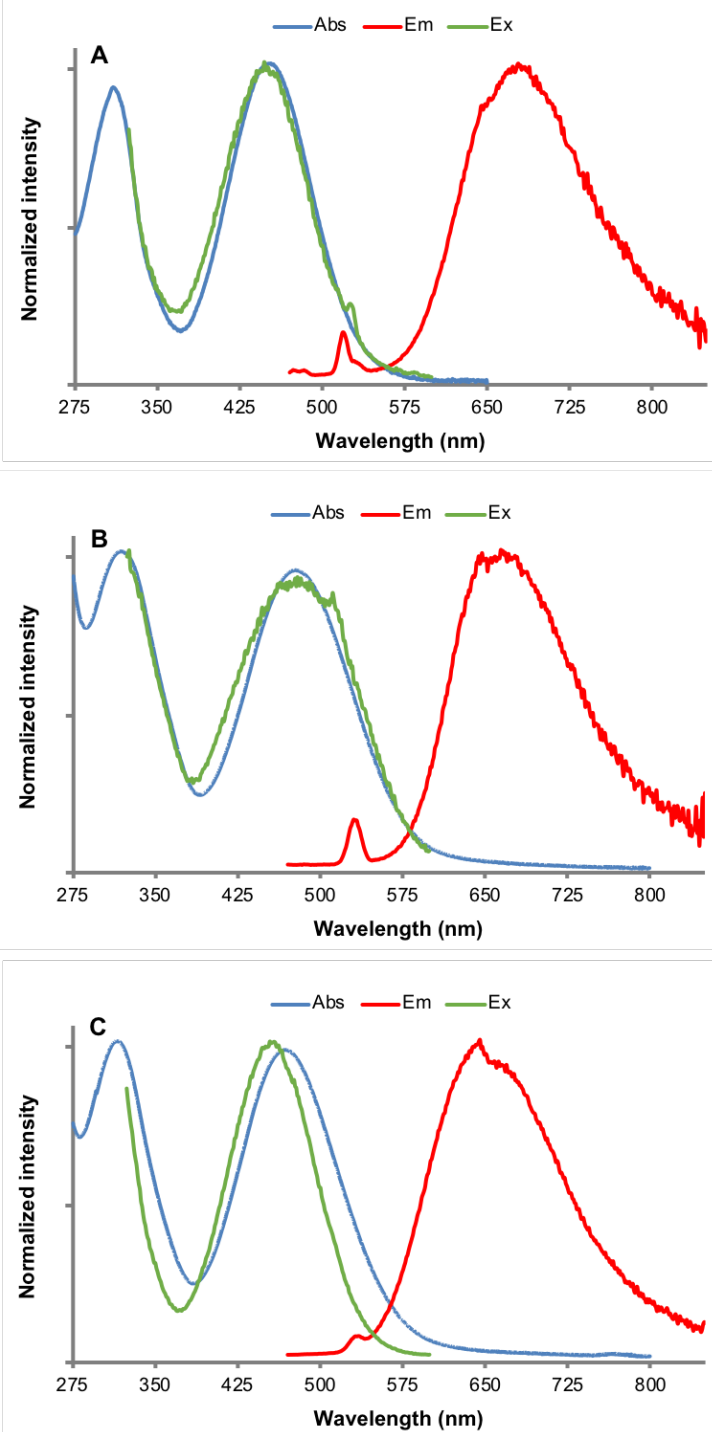

Fig. 2. Normalized absorption (blue), excitation (Em. $625 \mathrm{~nm}$, slit $5 \mathrm{~nm}$, green) and emission (Ex. $450 \mathrm{~nm}$, slit $5 \mathrm{~nm}$, red) spectra of PTZ-coumarin hybrid dye 10 in $\mathrm{MeOH}(\mathrm{A}), \mathrm{PBS}(\mathrm{B})$ and PBS + Tween $^{\circledR} 80(\mathrm{C})$ at $25^{\circ} \mathrm{C}$. Please note: peak at $519 \mathrm{~nm} / 530 \mathrm{~nm}$ is assigned to Raman scattering.

As already reported by Chen et al. for BZT derivatives 17 [8a], all spectral features of PTZ-coumarin hybrids $\mathbf{1 0}, \mathbf{1 5}$ and $\mathbf{1 6}$ are characteristic of photoactive molecules where strong internal charge transfer (ICT) process operates: (1) broad structureless absorption and emission bands with full-width at half maximum
(FWHM) $\Delta \lambda_{1 / 2 \max }$ in the range $80-110 \mathrm{~nm}$ and 130-165 nm respectively, (2) huge Stokes' shift values, and (3) NIR-I emission with a very low fluorescence quantum yield in polar solvents. Concerning this latter point, it is important to specify that the standard used by Chen et al. (i.e., fluorescein in $\mathrm{EtOH}$ ) for the determination of relative fluorescence quantum yield of $\mathbf{1 7}$ was not really the most suited because its absorption/emission curves do not really display similarities with those of this class of ICT-based compounds. We found that tris(2,2'-bipyridyl)ruthenium dichloride $\left(\mathrm{Ru}\left(\mathrm{bpy}_{3}\right) \mathrm{Cl}_{2}\right)$ in air-saturated water is more suitable for such determinations. Somewhat unexpectedly, the replacement of $n$-butyl substituent by a polar pendant arm is not having a positive effect on emissive effectiveness in aq. media. Indeed, in the concentration range used for fluorescence measurements $\left(10^{-7} \mathrm{M}\right)$, no formation of non-emissive $\mathrm{H}$-type aggregates as evidenced by the good matching between the absorption and excitation spectra recorded in PBS, was observed whatever the $\mathrm{N}$-substituent introduced onto the PTZ scaffold (Fig. 2 and Figs S40-S42 and S48-S50). Further molecular motions of trimethylpropylammonium and sulfobetain moieties could promote non-radiative deactivation and may explain the decrease of quantum yields compared to those determined with N-butyl derivative 10[11a]. Likewise, addition of Tween ${ }^{\circledR} 80(300 \mu \mathrm{M})$ in aq. buffer does not have a positive impact on fluorescence efficiency of these ICT-based fluorophores. Furthermore, in the present case, we were not able to use a more biorelevant disaggregating agent such as bovine serum albumin (BSA, typically added to PBS at a content of $5 \%(\mathrm{w} / \mathrm{v})$ to simulate body fluid) because emission spectrum of PBS $+5 \%$ BSA solution displays an intense broad band centered at $530 \mathrm{~nm}$ that partly overlap emission band of 10, 15 and 16. Despite their poor fluorescence in aq. media, we finally examined the ability of these phenothiazine derivatives to act as effective fluorogenic chemodosimeters for detection of reactive oxygen species (ROS).

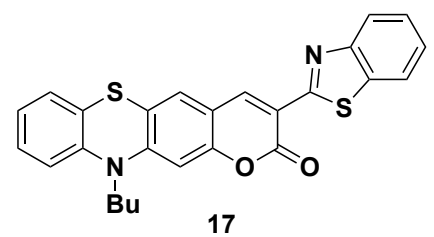

Sensing response of PTZ-coumarin hybrid dyes to $\mathrm{HClO} / \mathrm{ClO}^{-}$ analyte

The need for a comprehensive understanding of biological functions of ROS linked to their positive effects and adverse impacts on human health and the environment, has promoted the development of luminescent probe-based strategies for detecting such oxidative bioanalytes in vitro and in vivo [17]. This is true, in particular for hypochlorous acid $(\mathrm{HClO})$ that is produced by neutrophils and monocytes in vivo upon the reaction between $\mathrm{H}_{2} \mathrm{O}_{2}$ and $\mathrm{Cl}^{-}$ions catalyzed by myeloperoxidase [18]. This reaction also takes place in mitochondria and due to its $\mathrm{pKa}=7.46, \mathrm{HClO}$ is in equilibrium with $\mathrm{ClO}^{-}$under physiological conditions. Among the myriad of reaction-based fluorescent probes responsive to $\mathrm{HClO} / \mathrm{ClO}^{-}$, described in the literature [19], one of the preferred strategies involves functionalizing a fluorescent scaffold with a phenothiazine moiety that readily quenches its emission through the photoinduced electron transfer (PeT) mechanism. Hypochlorite-mediated oxidation of sulfur to sulfoxide prevents this PeT process and thus triggered fluorescence unveiling [6b-d, $6 f-i, 8 f, 20]$. Depending the chromophoric structure of the probe, an intensiometric or a ratiometric response can be obtained. In this context, we wished to examine the fluorogenic reactivity of PTZcoumarin hybrid dyes 10, 15 and 16 towards this ROS. Preliminary 
experiments have revealed that reaction of these phenothiazine derivatives with $\mathrm{NaOCl}$ (bleach) leads to a large hypsochromic shift $(-110 \mathrm{~nm},-161 \mathrm{~nm}$ and $-168 \mathrm{~nm}$ for $\mathbf{1 0}, 15$ and 16 respectively) of their emission maximum (data not shown). By analogy with the recent work of the Hou group [8f] and to avoid signal saturation, we selected the Ex/Em $400 / 520 \mathrm{~nm}$ pair for timedependent fluorescence analyses and to highlight the ratiometric behavior of 10, 15 and 16. On treatment of the three probes with 1 equiv. of $\mathrm{ClO}^{-}$in $\mathrm{PBS}(\mathrm{pH} 7.3)$ at $25^{\circ} \mathrm{C}$, an immediate and dramatic fluorescence enhancement at $520 \mathrm{~nm}$ was observed in each case. The most substantial increase in green fluorescence emission intensity was obtained with cationic PTZ-based probe 15. Conversely, in vitro assays conducted with zwitterionic PTZbased probe $\mathbf{1 6}$ has led to the least spectacular fluorogenic response. Furthermore, no significant fluorescence signal changes were observed in the absence of ROS, confirming the stability of the three ratiometric probes $\mathbf{1 0}, \mathbf{1 5}$ and $\mathbf{1 6}$ in PBS.

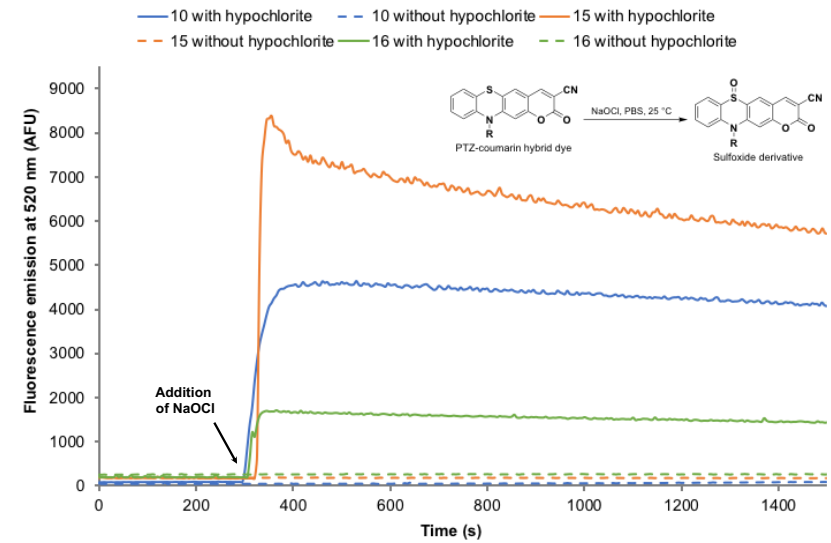

Fig. 3. Fluorescence emission time course (Ex/Em 400/520 nm, slit 2 nm) of PTZ-coumarin hybrid dyes 10, 15 and 16 (concentration: $2.0 \mu \mathrm{M}$ ) in the presence of hypochlorite ions (1 equiv.) in $\mathrm{PBS}(\mathrm{pH} 7.3)$ at $25^{\circ} \mathrm{C}$.

In order both to have an accurate idea of the conversion rate of such fluorogenic S-oxidation processes and to gain insights into the sensing mechanism through addressing issues related to the formation of a single or several oxidized species and the possible existence of further reactions triggered by this oxidation event, each reaction mixture was first subjected to RP-HPLCfluorescence analyses (see Supplementary data, Fig. S63-S75). Under acidic conditions (i.e., linear gradient of $\mathrm{MeCN}$ in aq. formic acid $0.1 \%, \mathrm{pH} 2.5$, as eluent) used for these analyses, the starting ICT-based probe 10 was detected on both Ex/Em channels $\left(400 / 520 \mathrm{~nm}\right.$ and $\left.450 / 700 \mathrm{~nm}, t_{\mathrm{R}}=5.7 \mathrm{~min}\right)$. After treatment with 1 equiv. of $\mathrm{ClO}^{-}$, a new major peak at $t_{\mathrm{R}}=4.6 \mathrm{~min}$ was detected, characterized by an intense emission at $520 \mathrm{~nm}$ and a negligible emission at $700 \mathrm{~nm}$, that was assigned to sulfoxide derivative. When the S-oxidation reaction was conducted with 10 equiv. or 100 equiv. of $\mathrm{ClO}^{-}$, a slight decrease of peak intensity or its complete disappearance was observed (see Supplementary data, Figs. S66-S67). That would suggest that sulfoxide derivative may undergone over-oxidation (formation of sulfone derivative?) and subsequent degradation of PTZ heterocycle. RP-HPLCfluorescence results obtained with cationic PTZ derivative $\mathbf{1 5}$ are quite similar (see Supplementary data, Figs. S68-S70, $t_{\mathrm{R}}=3.3 \mathrm{~min}$ and $3.9 \mathrm{~min}$ for sulfoxide and starting PTZ derivatives respectively). Conversely, a less substantial result was revealed with zwitterionic PTZ derivative 16 even a new peak $\left(t_{\mathrm{R}}=3.4 \mathrm{~min}\right)$ assigned to sulfoxide product was detected. The large remaining amount of $\mathbf{1 6}$ observed on the elution profile (see Supplementary data, Figs. S71-S73, $t_{\mathrm{R}}=3.9 \mathrm{~min}$ ) highlighted the poor conversion rate for this S-oxidation reaction. To confirm that the reaction between the probes $\mathbf{1 0}, \mathbf{1 5}$ and 16 and $\mathrm{ClO}^{-}$led to the formation of a sulfoxide derivative, the same mixtures were next analyzed by RP-HPLC-MS (see Supplementary data, Figs. S76-S91). The partial disappearance of the probe $\mathbf{1 0}$ peak $\left(t_{\mathrm{R}}=5.6 \mathrm{~min}\right)$ and the formation of sulfoxide derivative $\left(t_{\mathrm{R}}=4.6 \mathrm{~min}\right)$ was clearly observed and the structure of this latter green-emissive fluorophore was supported by MS-ESI+ data (both in "full scan" and single ion monitoring (SIM) modes). Interestingly, we also noted the formation of other minor products, one of which at $t_{\mathrm{R}}=$ $3.4 \mathrm{~min}$ was possibly identified as the sulfinic acid derivative or more probably the carboxamide derivative (MS(ESI +$): m / z=$ $383.2[\mathrm{M}+\mathrm{H}]^{+}$, calcd for $\mathrm{C}_{20} \mathrm{H}_{19} \mathrm{~N}_{2} \mathrm{O}_{4} \mathrm{~S}^{+}$383.1, see Fig. S90). Indeed, the nitrile moiety introduced onto the $\mathrm{C}-3$ position of coumarins, is prone to facile hydrolysis [21]. The same valuable information has been gathered with the cationic PTZ derivatives (see Supplementary data, Figs. S83-S85 and S91, $t_{\mathrm{R}}=3.0 \mathrm{~min}, \mathrm{~m} / \mathrm{z}$ $=426.2[\mathrm{M}]^{+}$, and $t_{\mathrm{R}}=3.2 \mathrm{~min}, \mathrm{~m} / z=408.2[\mathrm{M}]^{+}$for the sulfoxide derivatives bearing - $\mathrm{CONH}_{2}$ and $-\mathrm{CN}$ as $\mathrm{C}-3$ substituent). We have also confirmed the presence of a small amount of sulfoxide derivative in blank experiment (i.e., incubation of probe in PBS alone) whose formation may arise from a photooxidation process (i.e., sulfide oxidation mediated by singlet oxygen, formed by triplet energy transfer to molecular oxygen since PTZ scaffold is known to be an effective photosensitizer) [6a]. Regarding the PTZcoumarin hybrid $\mathbf{1 6}$ bearing a sulfobetain pendant arm, its poor reactivity towards $\mathrm{ClO}^{-}$was further confirmed by these RP-HPLCMS analyses (see Supplementary data, Figs. S87-S89). Therefore, thanks to these complementary analytical tools, we have shown for the first time that fluorogenic reactions between PTZ-based probes and stoichiometric amount of $\mathrm{ClO}^{-}$is not a quantitative and unequivocal process. Furthermore, depending on the nature of $\mathrm{N}$ substituent (length and net electrostatic charge) of PTZ scaffold, the ability of sulfide moiety to be readily oxidized and thus both quality and intensity of the fluorogenic ratiometric response are dramatically impacted.

Table 1 Photophysical properties of PTZ-coumarin hybrid dyes studied in this work, determined at $25^{\circ} \mathrm{C}$.

\begin{tabular}{|c|c|c|c|c|c|c|}
\hline $\mathrm{Cmpd}^{a}$ & Solvent & $\lambda_{\max } \operatorname{Abs}(\mathrm{nm})$ & $\lambda_{\max } \operatorname{Em}(\mathrm{nm})$ & $\begin{array}{l}\text { Stokes' shift } \\
\left(\mathrm{nm} / \mathrm{cm}^{-1}\right)\end{array}$ & $\varepsilon\left(\mathrm{M}^{-1} \mathrm{~cm}^{-1}\right)$ & $\Phi_{\mathrm{F}}(\%)^{b}$ \\
\hline 10 & $\mathrm{MeOH}$ & 309,451 & 678 & $\begin{array}{c}369 / 17613 \\
227 / 7423\end{array}$ & 10800,11950 & 1.6 \\
\hline 10 & PBS & 310,478 & 664 & $\begin{array}{c}354 / 17198 \\
186 / 5860\end{array}$ & 10300,9850 & 2.8 \\
\hline 10 & PBS + Tween $^{\circledR} 80$ & 314,462 & 645 & $\begin{array}{c}331 / 16343 \\
183 / 6141\end{array}$ & 11550,11250 & 4.8 \\
\hline
\end{tabular}




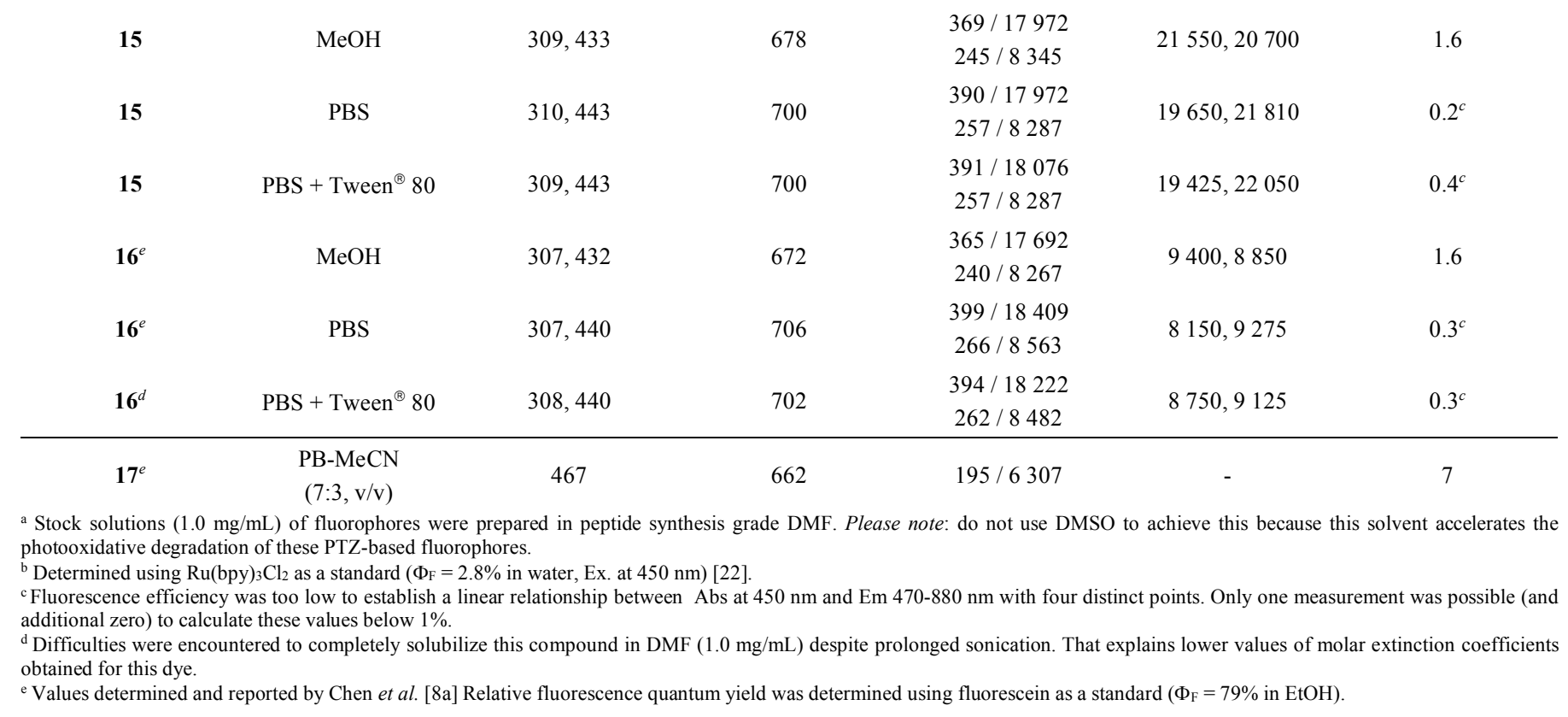

\section{Conclusion}

In summary, we have revisited and examplified $\mathrm{N}$-alkylation reaction of 2-methoxyphenothiazine 1 with the convertible 3dimethylaminopropyl substituent. Selective quaternarization of its tertiary amine moiety has been achieved and this $\mathrm{N}$ functionalization approach has opened the way for preparing novel hydrophilic PTZ-based pharmacophores and fluorophores. As an example, three PTZ-coumarin hybrid dyes with a marked ICT character, have been synthesized and photophysically characterized. Despite their modest fluorescence quantum yields in neutral aq. buffer, N-butyl and cationic PTZ derivatives $\mathbf{1 0}$ and 15 have been identified as practical fluorogenic probes for ratiometric detection of highly oxidative ROS, namely hypochlorite ions, through selective S-oxidation of their phenothiazine heterocycle. For the first time, the accurate analysis of such reaction by means of RP-HPLC coupled to fluorescence and mass detections, has enabled to show that this activity-based sensing strategy did not necessarily result in the quantitative formation of a single oxidized species (i.e., sulfoxide derivative). We are convinced that the implementation of such analytical methodology by (bio)chemists working in the field of reactionbased fluorescent probes would be helpful for deciphering precisely their activation mechanism and thus improving their performances.

\section{Declaration of Competing Interest}

The authors declare that they have no known competing financial interests or personal relationships that could have appeared to influence the work reported in this paper

\section{Acknowledgments}

This work is part of the project "Pharmacoimagerie et Agents Theranostiques", supported by the Universite de Bourgogne and Conseil Régional de Bourgogne through the Plan d'Actions Régional pour l'Innovation (PARI) and the European Union through the PO FEDER-FSE Bourgogne 2014/2020 programs. Financial support from Agence Nationale de la Recherche (ANR, AAPG 2018, DetectOP BChE, ANR-18-CE39-0014 and LuminoManufac-Oligo, ANR-18-CE07-0045), especially for the post-doc fellowships of Drs. Valentin Quesneau and Kévin Renault is also greatly acknowledged. Part of this work devoted to chemistry of DPP dyes was supported by the French "Investissements d'Avenir" program, project ISITE BFC (contract ANR-15-IDEX-0003), especially for the post-doc fellowship of Dr. Sébastien Jenni. Flavien Ponsot gratefully acknowledges the French Ministry of National Education, Higher Education and Research for his Ph. D. grant (2107-2020). The authors thank the "Plateforme d'Analyse Chimique et de Synthèse Moléculaire de l'Université de Bourgogne" (PACSMUB, http://www.wpcm.fr) for access to analytical instrumentation, especially Dr. Quentin Bonnin (CNRS, PACSMUB) for his help during variable temperature NMR experiments, COBRA lab (UMR CNRS 6014) and Iris Biotech company for the generous gift of some chemical reagents used in this work.

\section{Supplementary data}

Supplementary data (all synthetic procedures, spectroscopic and photophysical characterizations of PTZ-coumarin hybrid dyes described in this work) associated with this article can be found, in the online version:

\section{References and note}

A preprint was previously posted on ChemRxiv, see

[1] H. Caro US Pat. 204796, 1878.

[2] A. Bernthsen, Ber. Dtsch. Chem. Ges. 16 (1883) 28962904.

[3] E. A. Onoabedje, S. A. Egu, M. A. Ezeokonkwo, U. C. Okoro, J. Mol. Struct. 1175 (2019) 956-962.

[4] a) K. Pluta, B. Morak-Mlodawska, M. Jelen, Eur. J. Med. Chem. 46 (2011) 3179-3189; b) M. Wainwright, J. Braz. Chem. Soc. 26 (2015) 2390-2404; c) C. Gopi, M. D. Dhanaraju, Rev. J. Chem. 9 (2019) 95-126.

[5] a) Z.-S. Huang, H. Meier, D. Cao, J. Mater. Chem. C 4 (2016) 2404-2426; b) I. J. Al-Busaidi, A. Haque, N. K. Al Rasbi, M. S. Khan, Synth. Met. 257 (2019) 116189; c) S. Thokala, S. P. Singh, ACS Omega 5 (2020) 5608-5619.

[6] a) M. Barra, G. S. Calabrese, M. T. Allen, R. W. Redmond, R. Sinta, A. A. Lamola, R. D. Small, Jr., J. C. Scaiano, Chem. Mater. 3 (1991) 610-616; b) F. Liu, T. Wu, J. Cao, H. 
Zhang, M. Hu, S. Sun, F. Song, J. Fan, J. Wang, X. Peng, Analyst 138 (2013) 775-778; c) H. Xiao, K. Xin, H. Dou, G. Yin, Y. Quan, R. Wang, Chem. Commun. 51 (2015) 1442-5; d) L. Liang, C. Liu, X. Jiao, L. Zhao, X. Zeng, Chem. Commun. 52 (2016) 7982-7985; e) S. S. Deshpande, H. S. Kumbhar, G. S. Shankarling, Spectrochim. Acta, Part A 174 (2017) 154-163; f) D. Soni, S. Gangada, N. Duvva, T. K. Roy, S. Nimesh, G. Arya, L. Giribabu, R. Chitta, New J. Chem. 41 (2017) 5322-5333; g) M. Vedamalai, D. Kedaria, R. Vasita, I. Gupta, Sens. Actuators, B 263 (2018) 137-142; h) L. Wang, X. Chen, Q. Xia, R. Liu, J. Qu, Ind. Eng. Chem. Res. 57 (2018) 7735-7741; i) W. Wang, J.-Y. Ning, J.-T. Liu, J.-Y. Miao, B.-X. Zhao, Dyes Pigm. 171 (2019) 107708.

[7] J. Sheng, W. Shen, X. Yue, C. Huang CN Pat. 108250220A, 2018.

[8] a) W. Chen, X. Yue, W. Li, Y. Hao, L. Zhang, L. Zhu, J. Sheng, X. Song, Sens. Actuators, B 245 (2017) 702-710; b) W. Chen, L. Zhu, Y. Hao, X. Yue, J. Gai, Q. Xiao, S. Huang, J. Sheng, X. Song, Tetrahedron 73 (2017) 4529-4537; c) P. Hou, J. Wang, S. Fu, L. Liu, S. Chen, Spectrochim. Acta, Part A 213 (2019) 342346; d) P. Hou, J. Wang, S. Fu, L. Liu, S. Chen, Anal. Bioanal. Chem. 411 (2019) 935-942; e) W. Li, S. Zhou, L. Zhang, Z. Yang, H. Chen, W. Chen, J. Qin, X. Shen, S. Zhao, Sens. Actuators, B 284 (2019) 30-35; f) J.-T. Hou, B. Wang, P. Fan, R. Duan, X. Cao, L. Zhu, S. Wang, Dyes Pigm. 182 (2020) 108675; g) J.-T. Hou, B. Wang, S. Wang, Y. Wu, Y.-X. Liao, W. X. Ren, Dyes Pigm. 178 (2020) 108366; h) P. Hou, S. Chen, G. Liang, H. Li, H. Zhang, Spectrochim. Acta, Part A 229 (2020) 117866; i) S. Wang, B. Zhu, B. Wang, P. Fan, Y. Jiu, M. Zhang, L. Jiang, J.-T. Hou, Dyes Pigm. 173 (2020) 107933; j) W. Wang, N. Li, J.-T. Liu, J.-Y. Miao, B.X. Zhao, Z.-M. Lin, Dyes Pigm. 181 (2020) 108639; k) X. Yue, J. Wang, J. Han, B. Wang, X. Song, Chem. Commun. 56 (2020) 2849-2852; 1) J. Han, X. Liu, H. Xiong, J. Wang, B. Wang, X. Song, W. Wang, Anal. Chem. 92 (2020) 5134-5142; m) T. Zhang, L. Zhu, Y. Ma, W. Lin, Analyst 145 (2020) 1910-1914.

[9] a) M. Schmidt, M. Teitge, M. E. Castillo, T. Brandt, B. Dobner, A. Langner, Arch. Pharm. 341 (2008) 624-638; b) K. Kubota, H. Kurebayashi, H. Miyachi, M. Tobe, M. Onishi, Y. Isobe, Bioorg. Med. Chem. Lett. 19 (2009) 2766-2771; c) H. Prinz, B. Chamasmani, K. Vogel, K. J. Boehm, B. Aicher, M. Gerlach, E. G. Guenther, P. Amon, I. Ivanov, K. Mueller, J. Med. Chem. 54 (2011) 4247-4263; d) Y. Zhao, B. Huang, C. Yang, W. Xia, Org. Lett. 18 (2016) 3326-3329; e) R. Jin, C. L. Bub, F. W. Patureau, Org. Lett. 20 (2018) 2884-2887; f) K. Voegerl, N. Ong, J. Senger, D. Herp, K. Schmidtkunz, M. Marek, M. Mueller, K. Bartel, T. B. Shaik, N. J. Porter, D. Robaa, D. W. Christianson, C. Romier, W. Sippl, M. Jung, F. Bracher, J. Med. Chem. 62 (2019) 1138-1166.
[10] M. Nakanishi, G. Hasegawa JP Pat. 40009030, 1965.

[11] For selected examples, see: a) H. Itoi, T. Kambe, N. Kano, T. Kawashima, Inorg. Chim. Acta 381 (2012) 117-123; b) A. Romieu, C. Massif, S. Rihn, G. Ulrich, R. Ziessel, P.-Y. Renard, New J. Chem. 37 (2013) 1016-1027; c) N. Bisballe, B. W. Laursen, Chem. - Eur. J. (2020) in press, DOI: 10.1002/chem.202002457.

[12] S. Wang, A. Natrajan, RSC Adv. 5 (2015) 19989-20002. [13] a) D. G. Farnum, G. Mehta, G. G. I. Moore, F. P. Siegal, Tetrahedron Lett. 15 (1974) 2549-2552; b) M. Grzybowski, D. T. Gryko, Adv. Optical Mater. 3 (2015) 280-320; c) M. Kaur, D. H. Choi, Chem. Soc. Rev. 44 (2015) 58-77.

[14] W. Li, L. Wang, H. Tang, D. Cao, Dyes Pigm. 162 (2019) 934-950.

[15] a) S. Dollinger, S. Löber, R. Klingenstein, C. Korth, P. Gmeiner, J. Med. Chem. 49 (2006) 6591-6595; b) N. L. Agarwal, P. P. Mistri, N. M. Patel EP Pat. 2743263, 2014.

[16] M. Tasior, D. Kim, S. Singha, M. Krzeszewski, K. H. Ahn, D. T. Gryko, J. Mater. Chem. C 3 (2015) 1421-1446.

[17] For selected reviews, see: a) X. Chen, F. Wang, J. Y. Hyun, T. Wei, J. Qiang, X. Ren, I. Shin, J. Yoon, Chem. Soc. Rev. 45 (2016) 2976-3016; b) D. Andina, J.-C. Leroux, P. Luciani, Chem. - Eur. J. 23 (2017) 13549-13573; c) X. Jiao, Y. Li, J. Niu, X. Xie, X. Wang, B. Tang, Anal. Chem. 90 (2018) 533-555; d) L. Wu, A. C. Sedgwick, X. Sun, S. D. Bull, X.-P. He, T. D. James, Acc. Chem. Res. 52 (2019) 2582-2597.

[18] J. Zielonka, J. Joseph, A. Sikora, M. Hardy, O. Ouari, J. Vasquez-Vivar, G. Cheng, M. Lopez, B. Kalyanaraman, Chem. Rev. 117 (2017) 10043-10120.

[19] For selected reviews, see: a) S. Dong, L. Zhang, Y. Lin, C. Ding, C. Lu, Analyst 145 (2020) 5068-5089; b) T. Yudhistira, S. V. Mulay, Y. Kim, M. B. Halle, D. G. Churchill, Chem. - Asian J. 14 (2019) 3048-3084.

[20] a) C. Liu, Q. Wang, X. Jiao, H. Yao, S. He, L. Zhao, X. Zeng, Dyes Pigm. 160 (2019) 989-994; b) H. Li, Y. Miao, Z. Liu, X. Wu, C. Piao, X. Zhou, Dyes Pigm. 176 (2020) 108192; c) Y. Zhao, Y. Xue, J. Sun, H. Xuan, Y. Xu, Y. Cui, J. Dong, New J. Chem. 44 (2020) 12674-12679.

[21] a) F. Fringuelli, O. Piermatti, F. Pizzo, Synthesis (2003) 2331-2334; b) S. Debieu, A. Romieu, Org. Biomol. Chem. 13 (2015) 10348-10361.

[22] A. M. Brouwer, Pure Appl. Chem. 83 (2011) 2213-2228. 